\title{
One bite or two? A prospective trial comparing colonoscopy biopsy technique in patients with chronic ulcerative colitis
}

\author{
Lawrence C Hookey BSc MD ${ }^{1}$, David J Hurlbut MD², Andrew G Day MSc ${ }^{3}$, \\ Paul N Manley MD², William T Depew BSc MD ${ }^{1}$
}

LC Hookey, DJ Hurlbut, AG Day, PN Manley, WT Depew. One bite or two? A prospective trial comparing colonoscopy biopsy technique in patients with chronic ulcerative colitis. Can J Gastroenterol 2007;21(3):164-168.

BACKGROUND AND STUDY AIMS: Surveillance for mucosal dysplasia in patients with chronic ulcerative colitis requires numerous biopsies (often over 40). The aim of the present study was to determine if two biopsies could be obtained with jumbo forceps before removing them from the instrument (double biopsy technique), as opposed to one biopsy per pass, without sacrificing the histological quality of the biopsy material.

METHODS: Twelve patients with chronic ulcerative colitis underwent colonoscopy, and four-quadrant biopsies were obtained at $10 \mathrm{~cm}$ intervals. For biopsies at each interval, two quadrants were obtained using the double biopsy technique and the other two quadrants were obtained individually. Two pathologists blinded to the biopsy technique examined each biopsy for technical and diagnostic qualities. The primary outcome was the histological adequacy in the evaluation of dysplasia.

RESULTS: A total of 468 biopsies were obtained. A higher proportion of double-biopsy specimens were inadequate for dysplasia assessment compared with single-biopsy specimens $(\mathrm{OR}=2.78,95 \% \mathrm{CI} 1.37$ to $5.59 ; \mathrm{P}=0.005)$. In the double biopsy technique group, 14 samples were deemed inadequate due to actual tissue specimen loss, compared with eight samples in the single biopsy technique. However, when analysis was repeated using only the retrieved specimens, the double biopsy technique continued to be at higher risk of obtaining inadequate specimens ( $\mathrm{OR}=14.5,95 \% \mathrm{CI} 2.1$ to $98.7 ; \mathrm{P}=0.006$ ).

CONCLUSIONS: The results of the present study suggest that the double biopsy technique is vulnerable to specimen loss and reduced histological quality, and the adoption of this technique as an equivalent method for tissue sampling may be premature.
Un ou deux morceaux? Une étude prospective comparant les techniques de biopsie par coloscopie chez les patients atteints d'une colite ulcéreuse chronique

HISTORIQUE ET OBJECTIFS DE L'ÉTUDE : La surveillance de la dysplasie muqueuse chez les personnes atteintes de colite ulcéreuse chronique exige de nombreuses biopsies (souvent plus de 40). La présente étude visait à déterminer s'il était possible de prélever deux biopsies à l'aide de forceps géants avant de les retirer de l'instrument (technique de double biopsie), plutôt que d'effectuer une seule biopsie par prélèvement, sans sacrifier la qualité histologique de la matière prélevée.

MÉTHODOLOGIE : Douze patients atteints de colite ulcéreuse chronique ont subi une coloscopie, et on a prélevé des biopsies des quatre quadrants à intervalles de $10 \mathrm{~cm}$. Aux biopsies prélevées à chaque intervalle, on a obtenu deux quadrants au moyen de la technique de double biopsie, et deux quadrants par simple biopsie. Deux pathologistes qui n'étaient pas au courant de la technique de biopsie ont examiné chaque biopsie pour en déterminer les qualités techniques et diagnostiques. Le résultat primaire était la pertinence histologique dans l'évaluation de la dysplasie. RÉSULTATS : Au total, 468 biopsies ont été prélevées. Une plus forte proportion d'échantillons de double biopsie était inadéquate pour évaluer la dysplasie que d'échantillons de simple biopsie $(\mathrm{RR}=2,78,95 \%$ IC 1,37 à 5,59; $\mathrm{P}=0,005)$. Dans le groupe ayant subi une double biopsie, 14 échantillons ont été jugés inadéquats en raison d'une perte de l'échantillon de tissu, par rapport à huit échantillons de simple biopsie. Cependant, lorsque l'analyse était répétée seulement au moyen des échantillons prélevés, la technique de double biopsie risquait toujours davantage de fournir des échantillons inadéquats ( $R R=14,5,95 \%$ IC 2,1 à 98,7; P= 0,006).

CONCLUSIONS : Les résultats de la présente étude laissent supposer que la technique de double biopsie est vulnérable à une perte d'échantillon et à une diminution de la qualité histologique, et il est peut-être prématuré d'adopter cette méthode comme si elle équivalait à la simple biopsie.

\section{Key Words: Biopsy; Colonoscopy; Ulcerative colitis}

$\mathrm{T}$ issue sampling during endoscopic procedures is most often accomplished through pinch forceps biopsies of mucosae. Modifications in biopsy forceps' design may allow multiple biopsies to be taken in a single pass through the biopsy channel. One such modification is the addition of a central spike (Figure 1), which may prevent dislodgement of a specimen, thereby allowing a second additional sample to be obtained. Such a capability may be an advantage in procedures requiring numerous samples, such as screening for epithelial dysplasia in ulcerative colitis patients. In these patients, the American Gastroenterological Association recommends that four-quadrant biopsies be taken at $10 \mathrm{~cm}$ intervals from the cecum to the rectum (1). This usually demands 40 or more biopsy specimens per patient. One survey (2) of

${ }^{1}$ Gastrointestinal Diseases Research Unit; ${ }^{2}$ Department of Pathology; ${ }^{3}$ Clinical Research Unit, Kingston General Hospital, Queen's University,

Kingston, Ontario

Correspondence: Dr Lawrence C Hookey, Gastroenterology Division, Sydenham 4, Hotel Dieu Hospital, 166 Brock Street, Kingston,

Ontario K7L 5G2. Telephone 613-544-3400 ext 2288, fax 613-544-3114, e-mail hookeyl@hdh.kari.net

Received for publication April 19, 2006. Accepted June 13, 2006 
practice patterns reported that only $43 \%$ of colonoscopists take three or more biopsies at each level in these cases. A survey by Eaden et al (3) of gastroenterologists in the United Kingdom reported that adherence to such guidelines is even poorer, with a mere $12 \%$ of respondents reportedly taking more than 10 biopsies per colonoscopy, and even fewer (2\%) taking more than 20 per colonoscopy. Procedure time is likely a major determinant of sampling frequency, and a common practice is to use 'jumbo' forceps to obtain two samples at once, thereby shortening the time required for tissue sampling (4).

For a multiple biopsy technique to be clinically applicable, it is necessary to confirm that the diagnostic adequacy of the specimens is not compromised. A focused evaluation of the quality of multiple biopsy specimens has not been performed. A study (4) of a multiple biopsy technique in sampling mucosa of the upper gastrointestinal tract suggested that the risk of specimen loss with a double biopsy method was as great as $18 \%$, but that histological quality was preserved. Regrettably, the diagnostic criteria for histological quality in this study were not precisely defined. Chu et al (5) reported an evaluation of multiple types of biopsy forceps for single and multiple biopsy specimens, and although they did not note a significant difference in specimen quality or loss, the number of specimens in each individual group was relatively small, thereby leaving open the possibility that a moderate but not clinically insignificant difference was not detected. Moreover, these studies were not designed specifically to address a clinical scenario commonly requiring consideration of a multiple biopsy method.

The present prospective, diagnostically blinded study was designed to test the hypothesis that, compared with a traditional single biopsy method, there is an increased risk of specimen loss, as well as tissue distortion, using a double biopsy technique.

\section{METHODS}

Patients with documented chronic ulcerative colitis undergoing surveillance colonoscopy for dysplasia were invited to participate in the present study. Informed consent was obtained from all patients. The study was approved by the Queen's University (Kingston, Ontario) Health Sciences and Affiliated Teaching Hospitals Research Ethics Board.

Following routine preparation with either polyethylene glycol solution or oral sodium phosphate, colonoscopy of the cecum was performed in the usual manner. Four-quadrant biopsies were taken at $10 \mathrm{~cm}$ intervals, beginning in the cecum. At each biopsy level, two biopsies were taken using a double biopsy technique which involved taking two samples with one pass of the biopsy forceps. The remaining two quadrants were sampled individually using single passes of the forceps (single biopsy technique). The Olympus Jumbo Biopsy Forceps FB 13U-1 (Olympus Optical Co Ltd, Japan) were used throughout the study. All samples were immediately fixed, by an experienced gastrointestinal endoscopy nurse, through immersion in a solution of $10 \%$ buffered formalin. Samples were not mounted. Each bottle contained two specimens and were identical (either two specimens obtained via double biopsy technique or two specimens obtained via single biopsy technique), with no clear difference between those containing single biopsy or double biopsy specimens, thus ensuring blinding of the pathology technicians. Specimen containers were labelled and coded according to their distance from the cecum and the corresponding biopsy technique through which they were obtained.

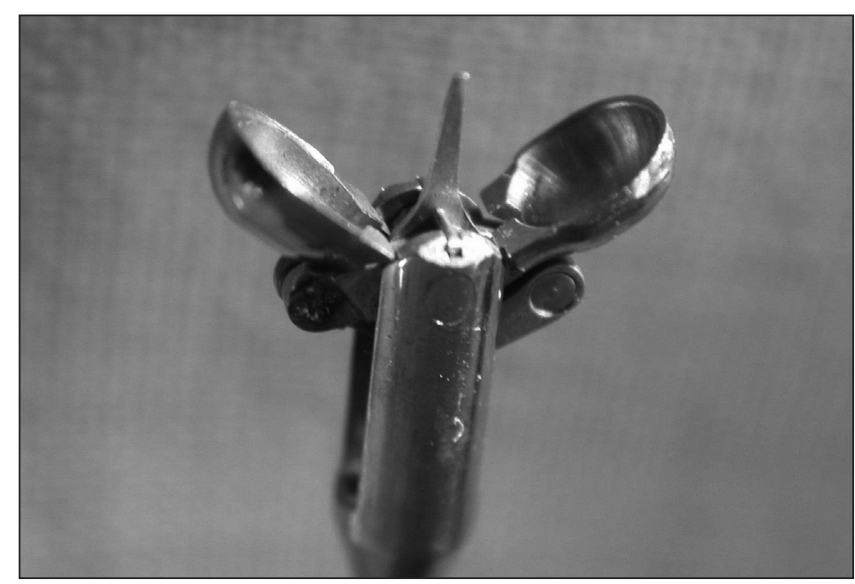

Figure 1) The Olympus Jumbo Biopsy Forceps FB 13U-1 (Olympus Optical Co Ltd, Japan). Note the central spike, which may allow for a second biopsy to be obtained while preventing dislodgement of the first tissue sample

Specimens received in the histopathology laboratory were routinely processed by paraffin embedding, with the contents of each specimen container embedded in a single block. Two slides containing multiple serial ribbons of $5 \mu \mathrm{m}$ thick sections, cut at multiple levels, were prepared from each block, and were stained with hematoxylin, phloxine and saffron. The deepest ribbon of the serial section on the deeper levelled slide (labelled slide ' 2 ') was used for pathological assessment.

Two experienced gastrointestinal pathologists independently reviewed all the samples in a blinded, random fashion. Each of the two mucosal biopsies per slide were individually assessed for size, technical quality and diagnostic utility. Size was defined as the maximum biopsy dimension (measured from the slide using an ocular micrometre and expressed to the nearest one-tenth of a millimetre). Technical quality assessment included biopsy depth (partial thickness mucosa: epithelium only or epithelium plus lamina propria; full thickness mucosa: epithelium plus lamina propria plus muscularis mucosa; and mucosa plus submucosa), biopsy fragmentation (present or absent), epithelial detachment (absent, present, less than $50 \%$, or greater than or equal to $50 \%$ ) and tissue crush (absent, present, less than $50 \%$, or greater than or equal to 50\%). Variables used to evaluate the diagnostic utility of each biopsy included the ability to assess for inflammation, crypt architecture and dysplasia, as well as the ability to identify the anatomical site (ie, identify biopsy as colonic mucosal tissue).

\section{Statistics}

The primary outcome was the histological adequacy for the identification of dysplasia. Assessments from both pathologists were combined to obtain a histologically inadequate single estimate of the OR of a specimen by the two methods. Lost specimens were considered inadequate in this component of the analysis. A generalized linear mixed effects model was used to account for the strong correlation of the adequacy assessments by the two pathologists, as well as potential intrapatient correlation created by the use of multiple measurements on a given patient by the same endoscopist. With the use of this testing strategy, there was no need to further correct for multiple testing within each patient. A two-sided $\mathrm{P}<0.05$ was considered significant. Intraobserver agreement for the primary outcome was calculated using kappa statistics. 


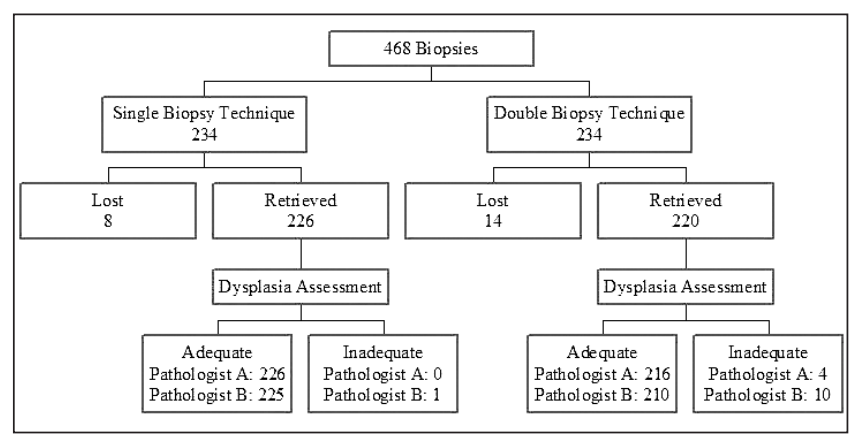

Figure 2) Flow chart illustrating biopsy technique-dependent outcome

In the present study, a large percentage of histologically inadequate specimens were lost tissue samples. Accordingly, a subgroup analysis was performed on the retrieved specimens to determine the effect of the double biopsy technique on histological quality.

Each secondary outcome was scored using either dichotomous variables or a rank order score. For these secondary outcomes, for each specimen, the least favourable score by the two pathologists was chosen for analysis. These data were analyzed using Fisher's exact test for binary outcomes and the exact Cochran-Armitage trend test for the ordinal outcomes. Because any difference between single and double biopsy techniques would be noteworthy, no adjustment for multiple comparisons was made in this subgroup analysis.

\section{RESULTS}

Four hundred sixty-eight biopsies were executed in 12 different patients by five experienced colonoscopists. One-half of the biopsies were obtained using the double biopsy technique and the other one-half using the standard single biopsy technique. The number of biopsies in each patient ranged from 32 to 52 (mean number of biopsies = 39) and was balanced between the two methods performed in each patient. The double biopsy method resulted in smaller specimens. The average maximum fixed dimension of the retrieved specimens for the double biopsy specimens was $3.5 \mathrm{~mm}$ (range $0.5 \mathrm{~mm}$ to $9.4 \mathrm{~mm}$ ), while for the single biopsy specimens the average was $4 \mathrm{~mm}$ (range $1.1 \mathrm{~mm}$ to $9.1 \mathrm{~mm})(\mathrm{P}<0.0001)$.

Pathologist A deemed 26 specimens (5.6\%) of the entire specimen pool inadequate for dysplasia assessment. Eighteen specimens (69\% of inadequate samples) were in the double biopsy group. Pathologist B deemed 33 specimens (7.1\%) inadequate, and 24 of those (73\% of inadequate samples) were taken with the double biopsy technique. Pathologist A rated $7.7 \%$ of double biopsy samples inadequate for dysplasia assessment, while pathologist B rated $10 \%$ inadequate (Figure 2). The inter-rater agreement for overall histological adequacy between the pathologists was strong (kappa=0.77, 95\% CI 0.64 to 0.89 ) The OR for an inadequate double biopsy technique specimen was estimated to be 2.78 (95\% CI 1.37 to 5.59; $\mathrm{P}=0.005)$ compared with the standard single biopsy technique.

Twenty-two of the inadequate designations were due to actual loss of the specimen. Fourteen double biopsy specimens $(6.0 \%)$ were lost compared with eight single biopsy specimens (3.4\%). The OR for loss using the double biopsy compared with the single biopsy technique was 1.8 (95\% CI 0.69 to $5.04 ; \mathrm{P}=0.27$ ). Comparison of the rates of inadequate specimens by the two methods was repeated, excluding the lost specimens. Using this subgroup of 446 specimens, pathologist A declared four of 220 double biopsy specimens (1.8\%) inadequate but zero of 226 single biopsy specimens. Pathologist B declared 10 of 220 double biopsy specimens (4.5\%) inadequate but only one of 226 single biopsy specimens $(0.4 \%)$ (Table 1). The 10 inadequate double biopsy specimens of pathologist $B$ included all four inadequate double biopsy specimens of pathologist $\mathrm{A}$. The results from the two pathologists were combined using the generalized linear mixed effects model. From this model, it was estimated that the OR of having an inadequate specimen is 14.5 -fold higher $(95 \% \mathrm{CI}$ 2.1 to $98.7 ; \mathrm{P}=0.006$ ) with the double biopsy method than with the single biopsy method, after excluding specimen loss as a factor.

Almost all the retrieved biopsy specimens inadequate for dysplasia assessment were superficial samples composed of strips of epithelium, either alone or with attached superficial lamina propria. One double biopsy specimen contained only ulcer exudate and granulation tissue without epithelium. There was no statistical increase in epithelial detachment, fragmentation or crush artifact within the retrieved double biopsy specimen group compared with the retrieved single biopsy specimen group. Inadequate samples that contained only strips of epithelium were scored as greater than $50 \%$ epithelial detachment when assessing this component of the biopsy technical quality; however, epithelial detachment of variable degree (usually less than 50\%) was a common finding seen in both study groups (Figures $3 \mathrm{~A}$ and $3 \mathrm{~B}$ ).

\section{DISCUSSION}

There currently exist numerous clinical scenarios in which multiple mucosal biopsies are required during an endoscopic procedure. One such instance is surveillance colonoscopy for dysplasia in ulcerative colitis. This is an accepted procedure requiring four-quadrant biopsies at $10 \mathrm{~cm}$ intervals (1). This results in a large number of total samples, and obtaining these samples is very time consuming. The ability to expedite this would appeal to both patients and endoscopists. One proposed method is to obtain two mucosal biopsies with one pass of

\section{TABLE 1}

Results of comparison of biopsy techniques for each technique $(n=234)$

\begin{tabular}{|c|c|c|c|c|c|c|}
\hline & \multicolumn{2}{|c|}{ Single biopsy technique } & \multicolumn{2}{|c|}{ Double biopsy technique } & \multirow[b]{2}{*}{ OR (95\% Cl) } & \multirow[b]{2}{*}{$\mathbf{P}$} \\
\hline & $\begin{array}{l}\text { Pathologist A } \\
\text { (n) }\end{array}$ & $\begin{array}{l}\text { Pathologist } B \\
\text { (n) }\end{array}$ & $\begin{array}{l}\text { Pathologist A } \\
\text { (n) }\end{array}$ & $\begin{array}{l}\text { Pathologist B } \\
\text { (n) }\end{array}$ & & \\
\hline Inadequate specimens & 8 & 9 & 18 & 24 & $2.78(1.37-5.59)$ & 0.005 \\
\hline Inadequate samples excluding lost specimens & 0 & 1 & 4 & 10 & $14.5(2.1-98.7)$ & 0.006 \\
\hline Lost specimens & 8 & - & 14 & - & $1.8(0.69-5.04)$ & 0.27 \\
\hline
\end{tabular}

OR was calculated using a generalized linear mixed effects model 
spiked biopsy forceps. The present prospective trial was performed to determine the diagnostic utility of such a technique.

The current study evaluated a large number of specimens and focused on one common clinically relevant scenario surveillance for dysplasia in patients with chronic ulcerative colitis. Previous studies (4-9) evaluating biopsy forceps have included heterogeneous study populations and indications for biopsies. Establishing a clear definition of an adequate biopsy is more difficult in such groups. The present study's primary outcome was histological adequacy of each biopsy to assess for dysplasia. Whether the entire set of biopsies is considered or only the retrieved specimens, the double biopsy technique resulted in significantly more inadequate specimens. It was also associated with a trend toward vulnerability to specimen loss, which contrasted with the results of Padda et al (4) and Chu et al (5). In retrieved specimens obtained with the double biopsy method, a reduction in histological quality due to superficial biopsy depth was also noted. Again, these results differ from other studies $(4,5)$. Potential reasons for these discrepancies in results include study design and statistical power to detect such differences. Our study has one of the largest number of specimens per biopsy forceps obtained and assessed, thus allowing detection of smaller, yet potentially important, differences. Also, our study was specifically designed to assess a single clinical setting with a relevant outcome - adequacy for detection of dysplasia.

Although the rate of diagnostic inadequacy using a double biopsy technique was low, the result may be clinically significant. In ulcerative colitis dysplasia surveillance, experts agree that the diagnostic yield increases with the number of biopsies obtained (1). In other words, dysplasia may only be found in a small number of biopsy specimens. While the ideal study would be powered to assess the detection rates of dysplasia, this would require a large number of patients and centres, as well as resources, which would probably be better directed elsewhere. The possibility of losing diagnostic information in as many as $10 \%$ of targeted biopsy sites, as occurred with the double biopsy technique in the present study, is concerning. However, the risk of increased specimen loss and diagnostic inadequacy must be gauged against increased efficiency, which has never been quantified. The relatively small number of patients in the present study, plus the added time for the processing of the study samples, did not allow comparison of procedure times using double or single biopsy techniques. It is possible that shorter colonoscopy times may lead to increased compliance among endoscopists to practice guidelines and a greater total number of biopsies taken.

Our findings suggest that even with jumbo biopsy forceps with a central spike, specimen inadequacy is significantly higher using the double biopsy technique. This leads to two questions: how common in everyday clinical practice in Canada is the practice of obtaining double biopsies, and how often is this done with normal, nonspecialized biopsy forceps? Is this practice more prone to sample loss and inadequacy, as our results suggest? Further study is required to address these questions.

\section{CONCLUSION}

The double biopsy technique, when used for dysplasia surveillance in patients with ulcerative colitis, results in a higher proportion of lost specimens and diagnostically

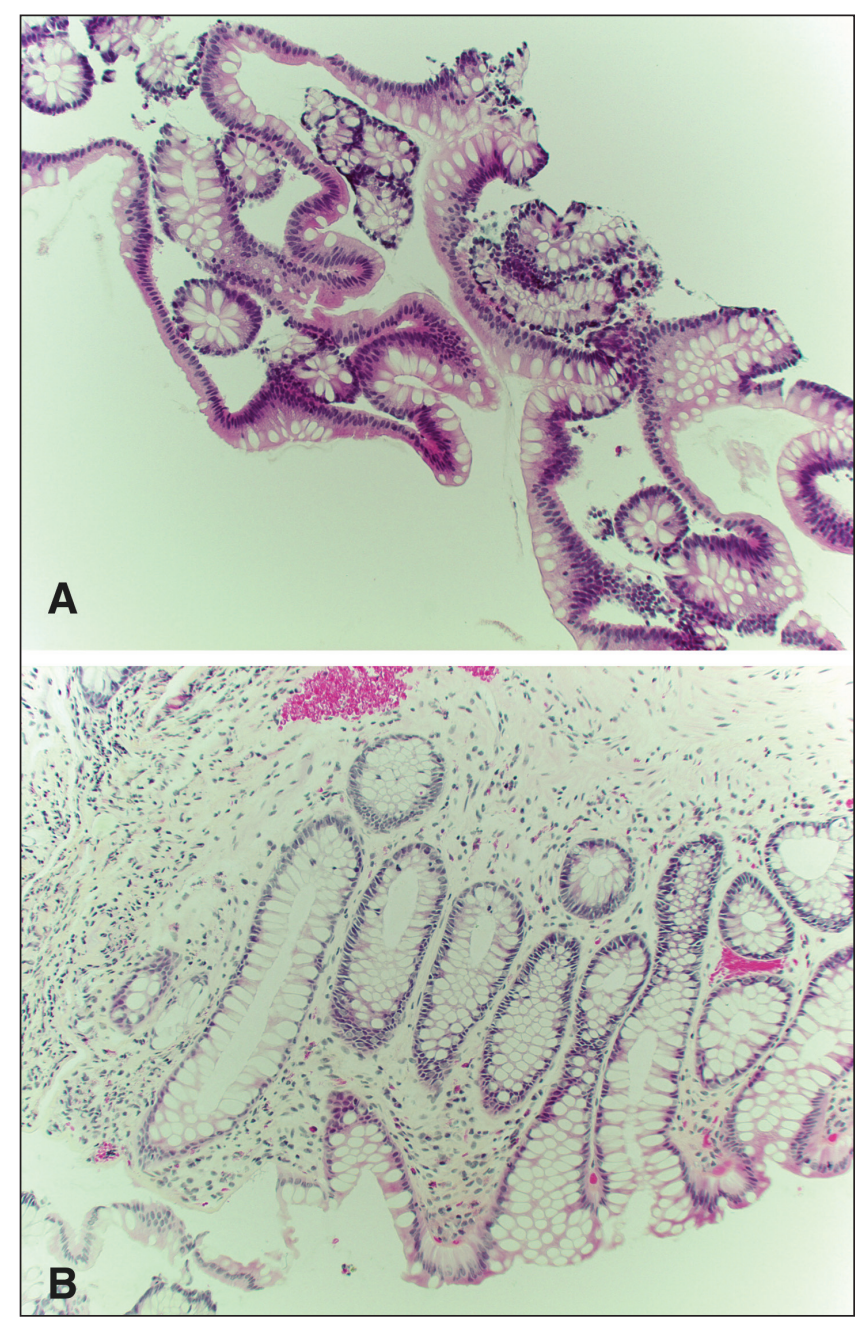

Figure 3) A Colonic biopsy obtained by the double biopsy technique, composed of only strips of detached columnar epithelium without other mucosal layers. This sample was assessed as inadequate for dysplasia assessment due to its very superficial depth (original magnification $\times 200$ ). B Full-thickness colonic mucosal biopsy obtained by the double biopsy method, which was scored as adequate for assessment of dysplasia. The minor degree of surface epithelial detachment observed was a common finding in biopsies from both study groups and did not impact on the adequacy of dysplasia assessment (original magnification $\times 200$ )

inadequate samples than the single biopsy technique. As many as $10 \%$ of double biopsy-targeted biopsy sites yielded inadequate diagnostic information for dysplasia, and this appeared to be more due to differences in specimen quality than specimen loss. This is a concerning proportion, considering the low overall incidence and random distribution of dysplasia in this disease. The adoption of double biopsies as an equivalent method for tissue sampling in this clinical setting may be premature. Newer forceps, specifically designed to obtain up to four biopsies with one pass, should undergo a similar evaluation in a prospective trial before their acceptance (5).

ACKNOWLEDGEMENTS: The authors thank the Hotel Dieu Hospital (Kingston, Ontario) endoscopy unit's nurses and staff for their assistance and cooperation in the present study. 


\section{REFERENCES}

1. Winawer S, Fletcher R, Rex D, et al; Gastrointestinal Consortium Panel. Colorectal cancer screening and surveillance: Clinical guidelines and rationale - Update based on new evidence. Gastroenterology 2003;124:544-60.

2. Bernstein CN, Weinstein WM, Levine DS, Shanahan F. Physicians' perceptions of dysplasia and approaches to surveillance colonoscopy in ulcerative colitis. Am J Gastroenterol 1995;90:2106-14.

3. Eaden JA, Ward BA, Mayberry JF. How gastroenterologists screen for colonic cancer in ulcerative colitis: An analysis of performance. Gastrointest Endosc 2000;51:123-8.

4. Padda S, Shah I, Ramirez FC. Adequacy of mucosal sampling with the "two-bite" forceps technique: A prospective, randomized, blinded study. Gastrointest Endosc 2003;57:170-3.

5. Chu KM, Yuen ST, Wong WM, et al. A prospective comparison of performance of biopsy forceps used in single passage with multiple bites during upper endoscopy. Endoscopy 2003;35:338-42.
6. Fantin AC, Neuweiler J, Binek JS, Suter WR, Meyenberger C. Diagnostic quality of biopsy specimens: Comparison between a conventional biopsy forceps and multibite forceps. Gastrointest Endosc 2001;54:600-4.

7. Kozarek RA, Attia FM, Sumida SE, et al. Reusable biopsy forceps: A prospective evaluation of cleaning, function, adequacy of tissue specimen, and durability. Gastrointest Endosc 2001;53:747-50.

8. Rizzo J, Bernstein D, Gress F. A performance, safety and cost comparison of reusable and disposable endoscopic biopsy forceps: A prospective, randomized trial. Gastrointest Endosc 2000;51:257-61.

9. Woods KL, Anand BS, Cole RA, et al. Influence of endoscopic biopsy forceps characteristics on tissue specimens: Results of a prospective randomized study. Gastrointest Endosc 1999;49:177-83. 


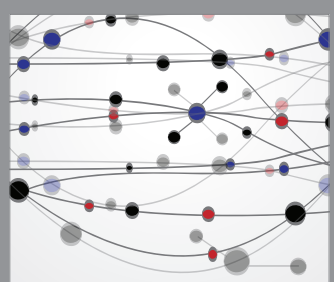

The Scientific World Journal
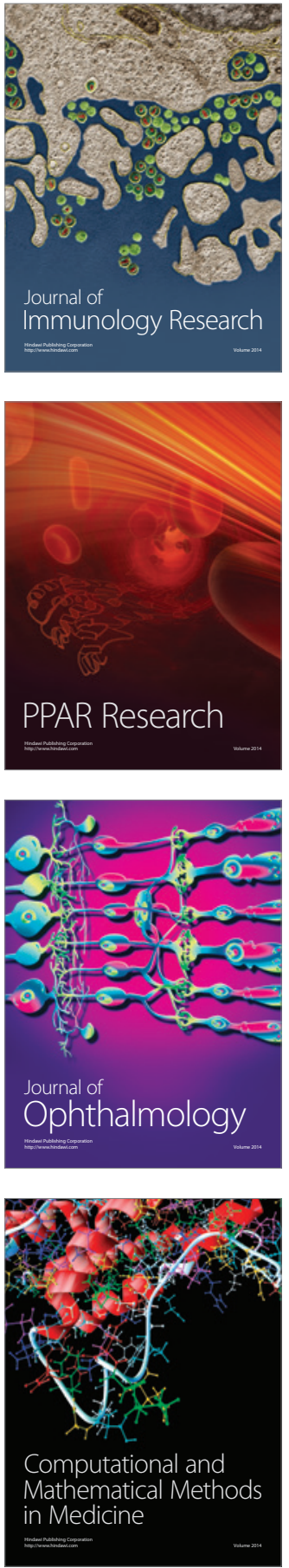

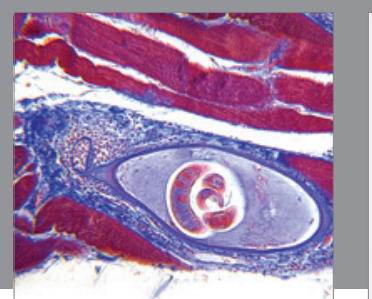

Gastroenterology Research and Practice

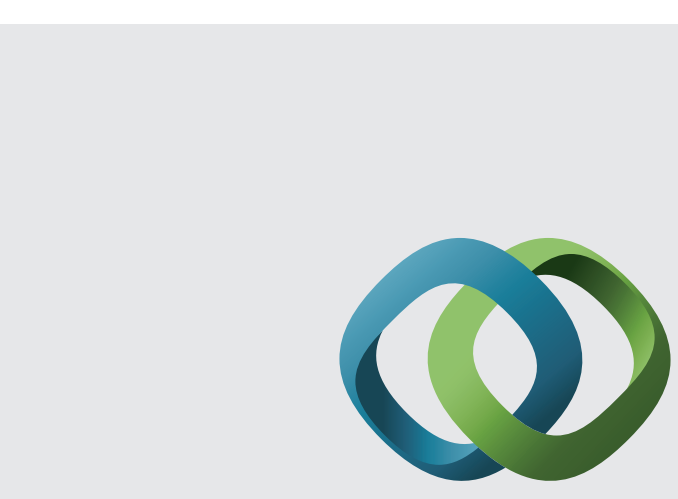

\section{Hindawi}

Submit your manuscripts at

http://www.hindawi.com
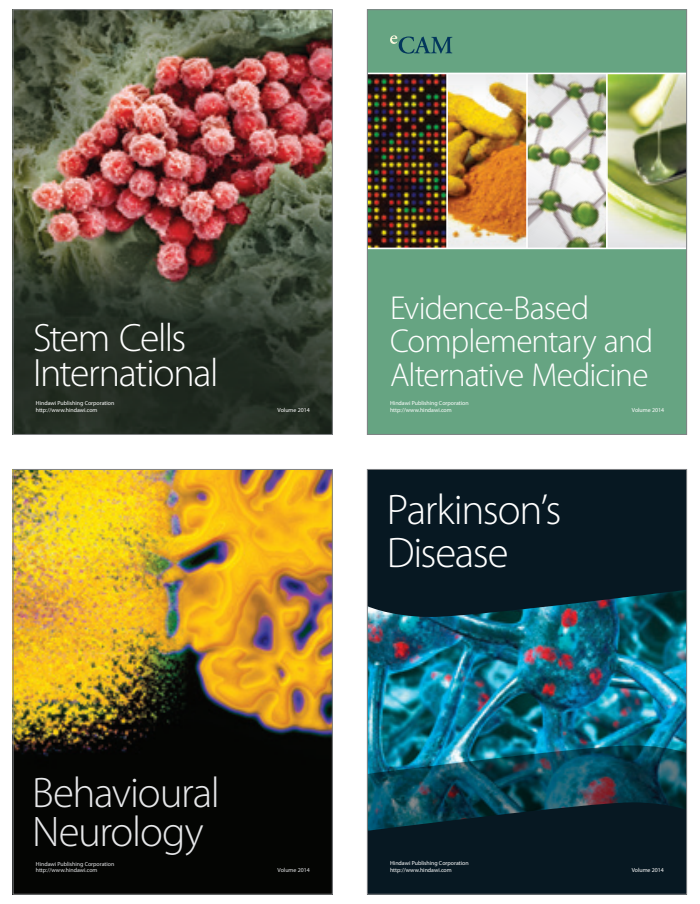
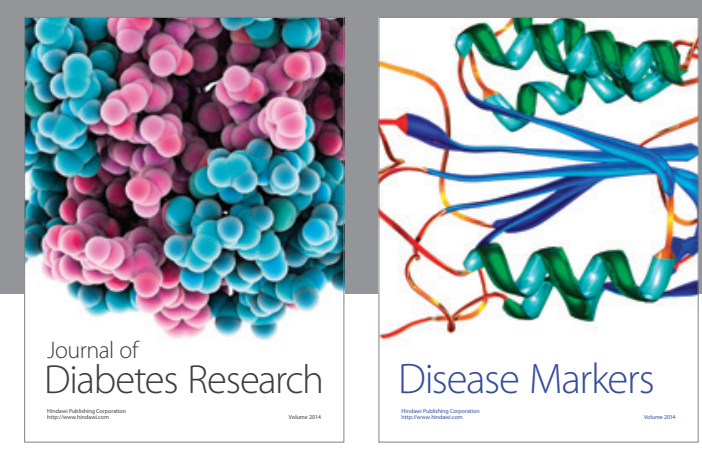

Disease Markers
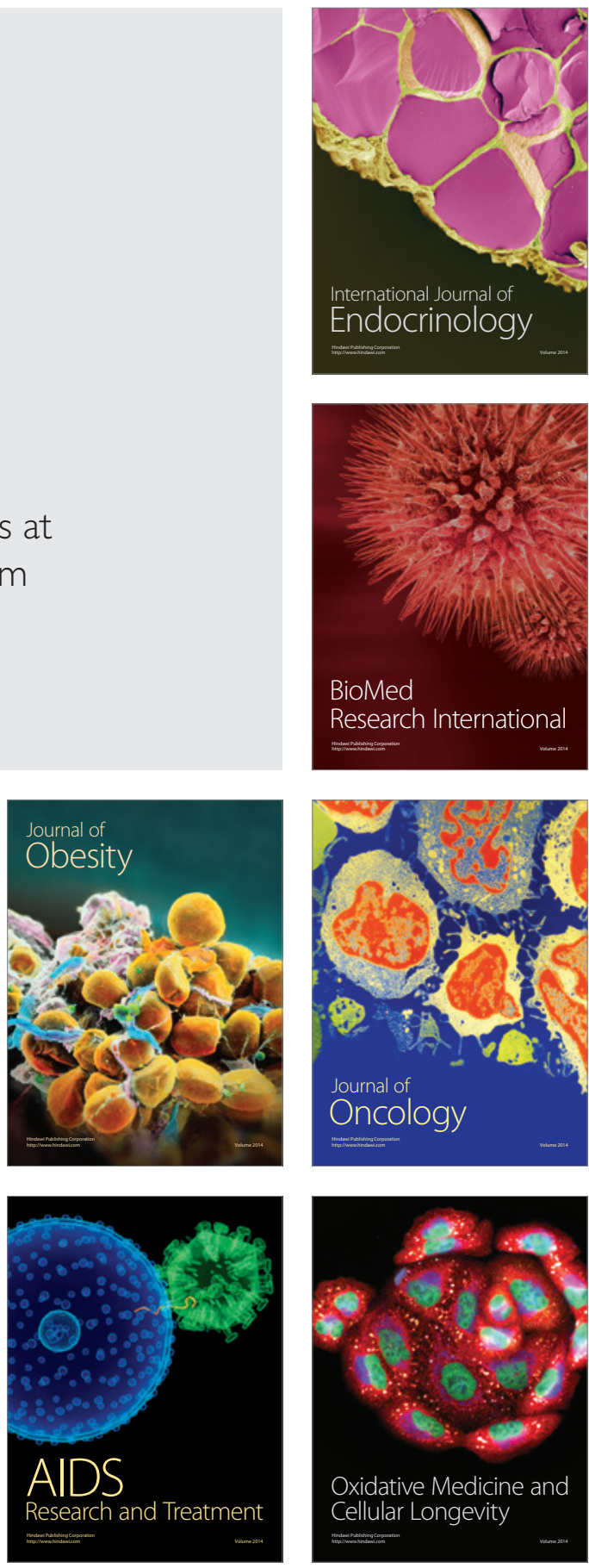